\title{
The effect of vitamin $E$ and oxidized fish oil on the nutrition of rainbow trout (Salmo gairdneri) grown at natural, varying water temperatures
}

\author{
By C. B. COWEY ${ }^{1}$, ELIZABETH DEGENER ${ }^{2}$, A. G. J. TACON², \\ A. YOUNGSON' AND J. G. BELL ${ }^{1}$ \\ ${ }^{1}$ Institute of Marine Biochemistry, St Fittick's Road, Aberdeen AB1 3RA and ${ }^{2}$ Institute of \\ Aquaculture, University of Stirling, Stirling FK9 $4 L A$
}

(Received 11 March 1983-Accepted 14 November 1983)

1. Groups of rainbow trout (Salmo gairdneri) of approximate mean initial weight $8 \mathrm{~g}$ were grown in outdoor tanks over a 14-week period at water temperatures between $12^{\circ}$ (start) and $6^{\circ}$ (end). Four diets were used. Two contained non-oxidized fish oil $(120 \mathrm{~g} / \mathrm{kg})$ with or without supplementary DL- $\alpha$ tocopheryl acetate and two contained moderately oxidized fish oil again with or without DL- $\alpha$-tocopheryl acetate. The measured selenium content of the diets was $0.10 \mathrm{mg} / \mathrm{kg}$.

2. No significant differences occurred as a consequence of the use of moderately oxidized oil compared with the corresponding treatments using non-oxidized oil. Significant differences did occur between dietary treatments that contained supplementary DL- $\alpha$-tocopheryl acetate and those that did not. These differences applied to weight gain, haematocrit, erythrocyte fragility, mortalities, liver and muscle tocopherol concentrations and lipid peroxidation of liver mitochondria in vitro. Liver glutathione peroxidase $(E C 1.11 .1 .9)$ activity was unaffected by the dietary treatments used and the proportions of fatty acids in polar lipids of liver and muscle were little changed by the diets used. Severe muscle damage occurred in trout given diets lacking supplementary DL- $\alpha$-tocopheryl acetate.

3. Previous experiments carried out on rainbow trout at a constant water temperature of $15^{\circ}$ (Hung et al. 1981 ; Cowey et al. 1981, 1983), using diets lacking supplementary vitamin E, did not lead to differences in weight gain, pathological changes or mortalities.

4. Vitamin $E$ requirement may increase as water temperature decreases; minimum dietary requirements for vitamin $\mathrm{E}$ measured at a constant water temperature of $15^{\circ}$ may not be valid under practical conditions where water temperatures vary over the year.

Few pathologies have been observed in rainbow trout (Salmo gairdneri) given diets containing fresh (non-oxidized) oil but deficient in vitamin E. Using partially defined diets containing linolenic and palmitic acids as the lipid component, Cowey et al. (1981) did not detect pathologies in vitamin E-deficient fish other than an increase in erythrocyte fragility and a decrease in haematocrit. Subsequently (Cowey et al. 1983), similar results were obtained when the fatty acid component of the diet was changed to polyunsaturated fatty acids $(100 \mathrm{~g} / \mathrm{kg})$ derived from white fish offal oil. Largely in agreement with this, Watanabe et al. (1981) failed to detect deficiency symptoms in trout given diets of low lipid content and, even when diets contained pollock liver oil or methyl esters of pollock liver oil $(150 \mathrm{~g} / \mathrm{kg})$, deficiency symptoms (convulsions and high mortalities) were observed in only one of the two experiments. By contrast a number of pathological changes occur in carp (Cyprinus carpio) deprived of vitamin $\mathrm{E}$ for $90 \mathrm{~d}$ or more, the most characteristic of which is apparent muscular dystrophy (Watanabe et al. 1970; Watanabe \& Takashima, 1977).

Hung et al. (1981) demonstrated that practical diets containing $75 \mathrm{~g}$ fresh herring oil $/ \mathrm{kg}$ and with a basal vitamin $\mathrm{E}$ content of $24 \mathrm{mg} / \mathrm{kg}$ afforded rapid growth without the occurrence of deficiency symptoms such as an increase in erythrocyte fragility. They inferred that where these conditions were met no further supplementation of the diet with vitamin $E$ or other anti-oxidant was necessary to prevent vitamin E deficiency in practical situations. Diets containing oxidized oil did, however, require supplementation with DL- $\alpha$-tocopheryl acetate to prevent the occurrence of these deficiency symptoms. 
Table 1. Composition ( $\mathrm{g} / \mathrm{kg}$ dry diet) of the experimental diets

\begin{tabular}{|c|c|c|c|c|}
\hline \multirow[b]{2}{*}{ Component } & \multicolumn{4}{|c|}{ Diet } \\
\hline & 1 & 2 & 3 & 4 \\
\hline Casein & 550 & 550 & 550 & 550 \\
\hline White dextrin & 100 & 100 & 100 & 100 \\
\hline Maize starch & 140 & 140 & 140 & 140 \\
\hline Vitamin premix* & 20 & 20 & 20 & 20 \\
\hline Mineral premix $\dagger$ & 40 & 40 & 40 & 40 \\
\hline Carboxymethyl cellulose & 30 & 30 & 30 & 30 \\
\hline Fish oil, fresh & 120 & 120 & 0 & 0 \\
\hline Fish oil, moderately oxidized & 0 & 0 & 120 & 120 \\
\hline DL- $\alpha$-Tocopheryl acetate & 0.4 & 0 & 0.4 & 0 \\
\hline Measured tocopherol content $(\mathrm{mg} / \mathrm{kg})$ & $395 \cdot 2$ & $18 \cdot 4$ & $388 \cdot 4$ & $7 \cdot 4$ \\
\hline Peroxide value of lipid at start $(\mathrm{mmol} / \mathrm{kg})$ & $2 \cdot 0$ & $2 \cdot 0$ & $47 \cdot 0$ & $47 \cdot 0$ \\
\hline Peroxide value of lipid at end $(\mathrm{mmol} / \mathrm{kg})$ & $7 \cdot 8$ & $117 \cdot 0$ & $210 \cdot 1$ & $333 \cdot 3$ \\
\hline
\end{tabular}

* Supplied (mg/kg diet): thiamin hydrochloride, 50; riboflavin, 50; calcium pantothenate, 100; nicotinic acid, 200 ; pyridoxine hydrochloride, 40 ; biotin, 6 ; folic acid, 15; cyanocobalamin, $0 \cdot 1$; inositol, 2000; ascorbic acid, 1000; choline chloride, 4000; menadione, 40; $p$-amino benzoic acid, 50; vitamin $A$ acetate, 2000 i.u.; vitamin $D_{3}$, 1000 i.u.

+ Supplied $\left(\mathrm{g} / \mathrm{kg}\right.$ diet): $\mathrm{CaHPO}_{4} \cdot 2 \mathrm{H}_{2} \mathrm{O}, 29 ; \mathrm{MgSO}_{4} \cdot 7 \mathrm{H}_{2} \mathrm{O}, 5 \cdot 1 ; \mathrm{KCl}, 2 \cdot 0 ; \mathrm{NaCl}, 2 \cdot 4 ; \mathrm{FeSO}_{4} \cdot 7 \mathrm{H}_{2} \mathrm{O}, 1 \cdot 0 ;$ $\mathrm{ZnSO}_{4} .7 \mathrm{H}_{2} \mathrm{O}, 0 \cdot 22 ; \mathrm{CuSO}_{4} .5 \mathrm{H}_{2} \mathrm{O}, 0.03 ; \mathrm{MnSO}_{4} \cdot 4 \mathrm{H}_{2} \mathrm{O}, 0 \cdot 105 ; \mathrm{CoSO}_{4} .7 \mathrm{H}_{2} \mathrm{O}, 0.019 ; \mathrm{CaIO}_{3} .6 \mathrm{H}_{2} \mathrm{O}, 0 \cdot 012 ; \mathrm{CrCl}_{2}$, $0 \cdot 0051$.

The experiments of Watanabe et al. (1981) were carried out at temperatures of 16-22\%, those of Hung et al. (1981) and Cowey et al. (1981, 1983) at a constant $15^{\circ}$. As trout inhabit waters at considerably lower temperatures than $15^{\circ}$, both in nature and in commercial practice, the experiment described in this paper was carried out in outdoor tanks at water temperatures $\left(12-6^{\circ}\right)$ occurring in North Britain in late summer and autumn. The object was to determine the necessity, or otherwise, of supplementation with vitamin $E$ of diets containing either fresh or oxidized oil under typical rearing conditions. The results demonstrate that under these environmental conditions pathologies, including severe muscle damage, occur in trout given diets containing fresh as well as moderately oxidized oil unless supplemental vitamin $\mathrm{E}$ is supplied.

\section{MATERIALS AND METHODS}

\section{Diets and fish}

Four experimental diets were used and their compositions are shown in Table 1. Two $\mathrm{kg}$ of each diet was prepared in dry (powder) form; $750 \mathrm{ml}$ water were added to and mixed with this powder and pellets were formed from the resulting paste, they had a moisture content in the range $30-32 \%$ for the four diets. All diets were stored at $-20^{\circ}$ until fed. The oil used was a non-stabilized (i.e. containing no added anti-oxidants) fish body oil (Stearine; Marfleet Refinery, Hull) with an iodine value of 98.8 and a peroxide value of $2.0 \mathrm{mmol} / \mathrm{kg}$. The oil was moderately oxidized by heating at $100^{\circ}$ for $7 \mathrm{~h}$ with constant aeration (compressed air) and continuing the aeration for a further $14 \mathrm{~h}$ without heat. Although this procedure led to an increase in peroxide value (Table 2) the extent of the oxidation was limited as shown by the presence of appreciable amounts of tocopherol; also the iodine value was unchanged (Table 2). In line with this, the fatty acid compositions of the fresh and oxidized oils were sensibly the same (Table 3). During the course of the 14-week experiment the peroxide value of lipid in diets 2,3 and 4 increased appreciably (Table 1). 
Table 2. Some characteristics of the fish oil used in the experimental diets

\begin{tabular}{lrc}
\hline & Fresh & Moderately oxidized \\
\hline Tocopherol $(\mathrm{mg} / \mathrm{kg})$ & 107 & 44 \\
Peroxide value $(\mathrm{mmol} / \mathrm{kg})$ & 2 & 47 \\
Iodine value & 99 & 97 \\
\hline
\end{tabular}

Table 3. Proportions of fatty acids $(\mathrm{g} / \mathrm{kg})$ in fish oil used in experimental diets

\begin{tabular}{lrc}
\hline Fatty acid & Fresh & Moderately oxidized \\
\hline $14: 0$ & $55 \cdot 3$ & $57 \cdot 6$ \\
$16: 0$ & $157 \cdot 0$ & $154 \cdot 0$ \\
$16: 1(n-9)$ & $87 \cdot 9$ & $90 \cdot 5$ \\
$16: 1(n-7)$ & $3 \cdot 1$ & $3 \cdot 1$ \\
$18: 0$ & $33 \cdot 4$ & $26 \cdot 2$ \\
$18: 1(n-9)$ & $255 \cdot 5$ & $253 \cdot 6$ \\
$18: 1(n-7)$ & $46 \cdot 5$ & $51 \cdot 4$ \\
$18: 2(n-6)$ & $23 \cdot 2$ & $18 \cdot 8$ \\
$18: 3(n-3)$ & $9 \cdot 3$ & $9 \cdot 0$ \\
$20: 0$ & $1 \cdot 3$ & $1 \cdot 3$ \\
$20: 1(n-9)$ & $72 \cdot 4$ & $75 \cdot 9$ \\
$20: 2$ & $2 \cdot 7$ & $2 \cdot 7$ \\
$20: 3$ & $3 \cdot 9$ & $4 \cdot 0$ \\
$20: 4(n-6)$ & $1 \cdot 7$ & $1 \cdot 8$ \\
$20: 5(n-3)$ & $42 \cdot 8$ & $43 \cdot 1$ \\
$22: 1(n-11)$ & $28 \cdot 4$ & $31 \cdot 2$ \\
$22: 1(n-9)$ & $5 \cdot 3$ & $55 \cdot 8$ \\
$22: 6(n-3)$ & $63 \cdot 0$ & $65 \cdot 1$ \\
\hline
\end{tabular}

The measured selenium contents of these diets varied between 0.092 and $0.108 \mathrm{mg} / \mathrm{kg}$ with a mean value of $0 \cdot 10 \mathrm{mg} / \mathrm{kg}$.

Rainbow trout of mean weight 7-9 $\mathrm{g}$ were obtained from Howietoun Fisheries, Bannockburn, Scotland, and weaned from a commercial diet to a purified diet (diet 1, Table 1), a procedure that required approximately 1 week. The fish were then randomly distributed at the rate of forty fish/tank among eight circular glass-fibre rearing tanks and the four diets were fed to duplicate groups (tanks) of fish. Each tank was of 401 capacity and was continuously supplied with artificially aerated (Venturi aspirator) tap water at a rate of $21 / \mathrm{min}$; the tanks were situated out of doors at the University of Stirling. Over the course of the experiment, which lasted 14 weeks (August-November), water temperature decreased gradually from $12^{\circ}$ to $6^{\circ}$ and fish were subject to a natural photoperiod.

Fish were given a fixed ration, usually at two feeds daily; no food was given on Sundays. On each occasion, food was given to the fish only for as long as they continued actively to seek and ingest it. Feeding rates were ( $\mathrm{g} / \mathrm{k}$ biomass per $\mathrm{d}$ ) weeks $0-2,75 ; 3-6,50 ; 7-8,40$; 9-14, 30. Fish were weighed individually at weekly intervals as described previously (Cowey et al. 1981).

\section{Analytical methods}

Tocopherol was extracted from diets either as described previously (Cowey et al. 1981) or as described by McMurray et al. (1980); both methods involved saponification prior to solvent extraction and gave similar values for all diets. Tocopherol in fish tissues was 
extracted as described previously (Cowey et al. 1981) and in both diet and tissue extracts tocopherol was resolved and measured by high performance liquid chromatography (Hung et al. 1980). Peroxide values and iodine values were measured in the oil by prescribed methods (Association of Official Analytical Chemists, 1975). The selenium content of the diets was measured as described by Hasunuma et al. (1982).

Lipids were extracted from liver and muscle of fish as described by Folch et al. (1957) and lipid classes separated by thin-layer chromatography on silica gel $\mathrm{G}$ plates $(0 \cdot 25 \mathrm{~mm}$ thickness) using hexane:diethyl ether:formic acid (140:60:1, by vol.) as the developing solvent. Methyl esters were prepared by sulphuric acid catalyzed methylation (Christie, 1973) of polar lipids, and the fatty acid methyl esters were separated and quantified by gas-liquid chromatography (Fractovap 4160, Erba Science Ltd, Swindon). A 50 m capillary column coated with free fatty acid phase (nitroerephtalic acid ester of carbowax $20 \mathrm{M}$ ) was used, hydrogen being the carrier gas. Temperature programming was from $150^{\circ}$, at $5^{\circ} / \mathrm{min}$, to $200^{\circ}(20 \mathrm{~min})$ and then from $200^{\circ}$, at $2^{\circ} / \mathrm{min}$, to $210^{\circ}(25 \mathrm{~min})$. Individual fatty acid methyl esters were identified by comparison with known standards and by reference to the results of Ackman \& Eaton (1978).

Erythrocyte fragility and ascorbic acid-stimulated lipid peroxidation of liver mitochondria were carried out as described previously (Cowey et al. 1981). Glutathione peroxidase (EC 1.11 .1 .9 ) activity was measured in whole blood (after lysing by addition of an equal volume of water and centrifuging at $5000 \mathrm{~g}$ for $15 \mathrm{~min}$ at $4^{\circ}$ ) and in liver cytosol as previously described (Cowey et al. 1981).

At the end of the experiment, five fish were removed at random from each tank. They were transported live to Aberdeen where measurements of lipid peroxidation in liver mitochondria and glutathione peroxidase activity were made on six individuals from each treatment (three each from duplicate tanks); fatty acid analysis of polar lipids from liver and muscle were made on three individuals (two fish from one of the duplicate tanks, one fish from the other). Erythrocyte fragility measurements were carried out at Stirling on three individuals randomly removed from each tank (six individuals per treatment). Tissues from another six individuals, chosen in similar random manner from each treatment, were immediately deep frozen before being transported in solid carbon dioxide to Aberdeen for tocopherol measurements. Finally liver, gill, spleen, muscle and brain were dissected from five fish from each treatment (three fish from one of the duplicate tanks and two fish from the other) and tissue slices were fixed in $4 \%(\mathrm{w} / \mathrm{v})$ buffered formalin for histological examination as described by Tacon \& Cooke (1980).

Statistical comparisons were made using the analysis of variance. Mean differences were obtained using Duncan's multiple range test (Duncan, 1955). Standard errors were calculated to identify the range of the means.

\section{RESULTS}

Mean final weights of trout, given diets 1 and 3 supplemented with vitamin $E$, were significantly greater $(P<0.05)$ than those of trout given diets 2 and 4 (Table 4 ), the highest specific growth rate occurring in trout given diet 3 and the lowest in trout given diet 4 . These values are reflected in the food conversion ratios and indicate that the main factor affecting growth rate in this experiment was the presence or absence of supplementary vitamin $\mathrm{E}$ in the diet. In addition, mortalities occurred only in those groups of fish given diets lacking supplementary vitamin $\mathrm{E}$. The moderately oxidized oil was as effective in sustaining growth rate as the fresh oil. This conclusion is borne out by the haematocrit values and the results of the erythrocyte fragility measurements, also shown in Table 4.

Concentrations of vitamin $\mathrm{E}$ in some of the trout tissues at the end of the experiment are shown in Table 5. The very marked differences evident in liver and muscle levels reflect 
Table 4. Growth results, haematocrit and erythrocyte fragility of rainbow trout given the experimental diets

\begin{tabular}{|c|c|c|c|c|c|}
\hline & \multicolumn{4}{|c|}{ Diet } & \multirow[b]{2}{*}{$\mathrm{SEM}^{*}$} \\
\hline & 1 & 2 & 3 & 4 & \\
\hline Mean initial weight $(\mathrm{g})$ & $9 \cdot 36^{a}$ & $7 \cdot 30^{a}$ & $7 \cdot 59^{a}$ & $7 \cdot 82^{a}$ & 1.02 \\
\hline Mean final weight $(\mathrm{g})$ & $51 \cdot 14^{b}$ & $37 \cdot 55^{a}$ & $48 \cdot 29^{b}$ & $35 \cdot 33^{a}$ & $3 \cdot 65$ \\
\hline Specific growth rate ${ }^{\dagger}(\% / \mathrm{d})$ & 1.73 & 1.67 & 1.89 & 1.54 & - \\
\hline Mean food intake ( $\mathrm{g} /$ fish per $\mathrm{d}$ ) & 0.43 & 0.37 & 0.43 & 0.39 & - \\
\hline Food conversion ratio (feed: gain) & 1.05 & $1 \cdot 20$ & 1.05 & 1.38 & - \\
\hline Mortalities & 0 & 3 & 0 & 6 & - \\
\hline Haematocrit $(\%)$ & $45 \cdot 5^{d}$ & $13 \cdot 2^{a}$ & $39^{\circ} 9^{c}$ & $20 \cdot 3^{b}$ & 1.78 \\
\hline Erythrocyte fragility $(\%)$ & $50 \cdot 8^{a}$ & $94.9^{b}$ & $57 \cdot 7^{a}$ & $73 \cdot 9^{a b}$ & 7.83 \\
\hline
\end{tabular}

$a, b, c$ Values in the same line with different superscripts were significantly different $(P<0 \cdot 05)$.

* SEM, Standard error of mean from error mean square.

$\dagger$ The percentage increase in body-weight $(W)$ per unit time $(T)$, determined as $\left[\left(\ln W_{2}-\ln W_{1}\right) \times 100\right] /\left(T_{2}-T_{1}\right)$.

Table 5. Concentrations of tocopherol in liver, muscle and whole blood from rainbow trout given the experimental diets

(Mean values with standard errors of mean from error mean square)

\begin{tabular}{|c|c|c|c|c|c|c|}
\hline \multirow[b]{2}{*}{ Diet } & \multicolumn{2}{|c|}{ Liver $(\mathrm{mg} / \mathrm{kg})$} & \multicolumn{2}{|c|}{ Muscle (mg/kg) } & \multicolumn{2}{|c|}{ Whole blood (mg/l) } \\
\hline & Mean & SEM & Mean & SEM & Mean & SEM \\
\hline 1 & $166 \cdot 2^{a}$ & $16 \cdot 20$ & $8.06^{a}$ & 0.48 & $21 \cdot 55^{a}$ & 4.41 \\
\hline 2 & $6 \cdot 4^{b}$ & 0.68 & $2 \cdot 48^{b}$ & 0.15 & $16 \cdot 71^{a}$ & 3.76 \\
\hline 3 & $109 \cdot 8^{a}$ & $6 \cdot 11$ & $6.08^{a}$ & 0.97 & $12 \cdot 15^{a}$ & 1.45 \\
\hline 4 & $6.7^{a}$ & $1 \cdot 33$ & $2 \cdot 35^{a}$ & 0.27 & $10 \cdot 79^{a}$ & $5 \cdot 10$ \\
\hline
\end{tabular}

$a, b$ Values in the same column with different superscripts were significantly different $(P<0 \cdot 01)$.

the dietary intake; no significant differences occurred in blood levels of vitamin $\mathrm{E}$ irrespective of intake. This contrasts with earlier results (Cowey et al. 1981) when there was a marked reduction in erythrocyte vitamin $E$ levels in trout given diets lacking supplementary vitamin E.

Liver glutathione peroxidase activity was not significantly different $(P>0 \cdot 1)$ in any of the experimental treatments (Table 6). Activity in the blood of trout given diet 4 containing moderately oxidized oil without supplementary vitamin $\mathrm{E}$ was significantly greater than that of trout give diet 3 containing added vitamin $\mathrm{E}(P<0 \cdot 05)$.

Little ascorbic acid-Fe ${ }^{3+}$ stimulated malondialdehyde was formed when mitochondria from livers of trout given diets 1 and 3 were incubated in vitro. Much more malondialdehyde was formed when hepatic mitochondria from treatments 2 and 4 were incubated. This result is probably a reflection of the vitamin $\mathbf{E}$ contents of livers for the different treatments (Table 5, Kornbrust \& Mavis, 1980).

The fatty acid compositions of polar lipids from liver and muscle of trout given the four experimental treatments are shown in Tables 7 and 8 . The most striking feature of the results from liver is the reduction in docosahexaenoic acid $(22: 6, n-3)$ in trout given diet 4 which is almost wholly compensated by an increase in oleic acid $(18: 1, n-9)$. No parallel changes 
Table 6. Glutathione peroxidase activity in liver and blood and ascorbic acid-Fe $\mathrm{F}^{3+}$ stimulated malondialdehyde formation in liver mitochondria from rainbow trout given the experimental diets

(Mean values with standard errors of mean from error mean square)

\begin{tabular}{|c|c|c|c|c|c|c|c|c|}
\hline & \multicolumn{8}{|c|}{ Diet } \\
\hline & \multicolumn{2}{|l|}{1} & \multicolumn{2}{|c|}{2} & \multicolumn{2}{|c|}{3} & \multicolumn{2}{|l|}{4} \\
\hline & Mean & SEM & Mean & SEM & Mean & SEM & Mean & SEM \\
\hline $\begin{array}{l}\text { GSH px in liver } \\
(\mu \mathrm{mol} / \mathrm{min} \text { per } \mathrm{g} \text { protein })\end{array}$ & $10 \cdot 59$ & $1 \cdot 12$ & $11 \cdot 79$ & $0 \cdot 33$ & 8.28 & 0.68 & $10 \cdot 27$ & 0.53 \\
\hline $\begin{array}{l}\text { GSH px in blood } \\
(\mu \mathrm{mol} / \mathrm{min} \text { per } \mathrm{g} \text { protein })\end{array}$ & $9 \cdot 71^{a b}$ & 1.33 & $\mathrm{~L}$ & & $7.89^{a}$ & 0.19 & $13 \cdot 67^{b}$ & 1.04 \\
\hline $\begin{array}{l}\text { Malondialdehyde formed } \\
(\mu \mathrm{mol} / \mathrm{mg} \text { protein in } 60 \mathrm{~min} \text { at } \\
\left.15^{\circ}\right)\end{array}$ & $0 \cdot 24^{a}$ & 0.008 & $14.96^{b}$ & $3 \cdot 31$ & $0 \cdot 25^{a}$ & $0 \cdot 88$ & $6 \cdot 55^{a b}$ & $4 \cdot 23$ \\
\hline
\end{tabular}

GSH px, glutathione peroxidase $(E C 1.11 .1 .9)$

$\mathrm{L}$, no sample available.

$a, b$ Values in the same line with different superscripts were significantly different $(P<0 \cdot 01)$.

Table 7. Proportions of principal fatty acids $(\mathrm{g} / \mathrm{kg})$ in polar lipids from livers of rainbow trout given the experimental diets

(Mean values with standard errors of mean from error mean square)

\begin{tabular}{|c|c|c|c|c|c|c|c|c|}
\hline \multirow{2}{*}{$\begin{array}{l}\text { Diet treatment... } \\
\text { Fatty acid }\end{array}$} & \multicolumn{2}{|c|}{1} & \multicolumn{2}{|c|}{2} & \multicolumn{2}{|c|}{3} & \multicolumn{2}{|c|}{4} \\
\hline & Mean & SEM & Mean & SEM & Mean & SEM & Mean & SEM \\
\hline $14: 0$ & 11.8 & 0.7 & $8 \cdot 8$ & 0.1 & 11.7 & $1 \cdot 0$ & 11.9 & 0.7 \\
\hline $16: 0$ & 152.9 & $2 \cdot 5$ & $138 \cdot 2$ & $1 \cdot 3$ & $141 \cdot 1$ & $8 \cdot 1$ & 140.9 & $3 \cdot 6$ \\
\hline $16: 1(n-9)$ & $12 \cdot 3$ & 0.9 & 11.0 & 0.2 & $13 \cdot 7$ & 0.7 & $13 \cdot 7$ & 0.6 \\
\hline $16: 1(n-7)$ & $34 \cdot 0$ & $6 \cdot 1$ & 30.7 & 0.5 & $30 \cdot 3$ & 1.6 & $39 \cdot 1$ & 0.8 \\
\hline $18: 0$ & $71 \cdot 8$ & $3 \cdot 0$ & $72 \cdot 3$ & $3 \cdot 5$ & $69 \cdot 4$ & $2 \cdot 7$ & 81.0 & $3 \cdot 4$ \\
\hline $18: 1(n-9)$ & $210 \cdot 0$ & $20 \cdot 5$ & 203.4 & $2 \cdot 2$ & 181.0 & $10 \cdot 5$ & $276 \cdot 3$ & $31 \cdot 4$ \\
\hline $18: 1(n-7)$ & 33.7 & $2 \cdot 2$ & $36 \cdot 7$ & $4 \cdot 1$ & 42.9 & 1.5 & $47 \cdot 3$ & $5 \cdot 3$ \\
\hline $20: 1(n-9)$ & $24 \cdot 7$ & $2 \cdot 4$ & $25 \cdot 6$ & $9 \cdot 2$ & 26.0 & 3.4 & 20.6 & 0.2 \\
\hline $20: 2$ & $38 \cdot 0$ & $4 \cdot 1$ & $43 \cdot 1$ & $3 \cdot 1$ & $63 \cdot 3$ & $3 \cdot 0$ & $73 \cdot 8$ & 8.9 \\
\hline $20: 3$ & $17 \cdot 5$ & 1.7 & $17 \cdot 3$ & $3 \cdot 1$ & $27 \cdot 1$ & $3 \cdot 5$ & $22 \cdot 0$ & 1.4 \\
\hline $20: 5(n-3)$ & $14 \cdot 7$ & 1.8 & $15 \cdot 3$ & 1.3 & 14.9 & 0.9 & $9 \cdot 4$ & $1 \cdot 2$ \\
\hline $22: 6(n-3)$ & $306 \cdot 3$ & $27 \cdot 0$ & 302.0 & $22 \cdot 0$ & 292.6 & 16.6 & $172 \cdot 1$ & 19.8 \\
\hline
\end{tabular}

were found in polar lipids from muscle, relative amounts of fatty acids in this fraction from the four treatments being very similar. This is a little surprising as pathologies were very obvious in muscle of treatments 2 and 4 but much less so in liver.

Histological examination of tissues from the four treatments revealed that the most severe changes occurred in the skeletal muscle of those fish receiving diets 2 and 4 lacking supplementary vitamin $\mathrm{E}$. The changes (Plates 1 and 2) consisted in an alteration of fibre size with the fibres being more rounded, partly swollen and partly shrunken. The degeneration of fibres was clear in both treatments 2 and 4 (Plates $1 b$ and $2 b$ ) but was much more marked in treatment 4 where there were zonal necrotic areas showing typical hyaline 
Table 8. Proportions of principal fatty acids $(\mathrm{g} / \mathrm{kg})$ in polar lipids from muscle of rainbow trout given the experimental diets

(Mean values with standard errors of mean from error mean square)

\begin{tabular}{|c|c|c|c|c|c|c|c|c|}
\hline \multirow{2}{*}{$\begin{array}{l}\text { Diet treatment... } \\
\text { Fatty acid }\end{array}$} & \multicolumn{2}{|c|}{1} & \multicolumn{2}{|c|}{2} & \multicolumn{2}{|c|}{3} & \multicolumn{2}{|c|}{4} \\
\hline & Mean & SEM & Mean & SEM & Mean & SEM & Mean & SEM \\
\hline $14: 0$ & $21 \cdot 5$ & $3 \cdot 4$ & $20 \cdot 1$ & 1.9 & $24 \cdot 0$ & $1 \cdot 3$ & $13 \cdot 3$ & $4 \cdot 2$ \\
\hline $16: 0$ & $161 \cdot 7$ & $10 \cdot 3$ & $169 \cdot 4$ & 4.0 & 146.9 & $4 \cdot 5$ & $146 \cdot 9$ & 9.8 \\
\hline $16: 1(n-9)$ & $10 \cdot 5$ & 0.5 & $9 \cdot 8$ & $1 \cdot 2$ & $12 \cdot 6$ & $2 \cdot 1$ & $11 \cdot 5$ & 0.4 \\
\hline $16: 1(n-7)$ & $71 \cdot 6$ & $4 \cdot 9$ & $50 \cdot 1$ & 8.7 & $67 \cdot 6$ & $1 \cdot 8$ & $53 \cdot 3$ & $2 \cdot 9$ \\
\hline $18: 0$ & $42 \cdot 1$ & $1 \cdot 8$ & $43 \cdot 4$ & $1 \cdot 0$ & $38 \cdot 8$ & 0.8 & $43 \cdot 6$ & $2 \cdot 4$ \\
\hline $18: 1(n-9)$ & $229 \cdot 2$ & 0.9 & $206 \cdot 4$ & $13 \cdot 8$ & $235 \cdot 0$ & $10 \cdot 7$ & $233 \cdot 3$ & $2 \cdot 6$ \\
\hline $18: 1(n-7)$ & $34 \cdot 8$ & 0.8 & $33 \cdot 0$ & 0.6 & $37 \cdot 7$ & $1 \cdot 1$ & $36 \cdot 0$ & 0.6 \\
\hline $20: 1(n-9)$ & $21 \cdot 1$ & $1 \cdot 5$ & $16 \cdot 8$ & 0.7 & $23 \cdot 6$ & $1 \cdot 1$ & 27.8 & $7 \cdot 4$ \\
\hline $20: 2$ & $13 \cdot 0$ & $2 \cdot 4$ & 14.0 & $1 \cdot 1$ & 15.9 & 0.4 & $18 \cdot 4$ & 0.8 \\
\hline $20: 3$ & $9 \cdot 9$ & 0.7 & $10 \cdot 7$ & 0.6 & $9 \cdot 9$ & $0 \cdot 1$ & $11 \cdot 5$ & 0.7 \\
\hline $20: 5(n-3)$ & $26 \cdot 6$ & $1 \cdot 3$ & $28 \cdot 9$ & 2.9 & $25 \cdot 1$ & 0.5 & 21.9 & 1.6 \\
\hline $22: 6(n-3)$ & $280 \cdot 6$ & $20 \cdot 5$ & $303 \cdot 7$ & $17 \cdot 0$ & $261 \cdot 3$ & $6 \cdot 2$ & $263 \cdot 3$ & $17 \cdot 5$ \\
\hline
\end{tabular}

degeneration with distinct eosinophilia. Both treatments also showed a cellular infiltration in the sub-pericardial area, some pycnotic nuclei were present and there was some vacuolization of the cytoplasm.

Some changes also occurred in the anterior region of the kidney from treatments 2 and 4 and this amounted to a generalized loss of haemopoietic tissue.

Differences between treatments were consistent in the duplicated tanks.

\section{DISCUSSION}

The substitution of a moderately oxidized oil for fresh oil in diets containing supplementary vitamin $\mathrm{E}$ ( $400 \mathrm{mg} \mathrm{DL}-\alpha$-tocopheryl acetate $/ \mathrm{kg}$ ) did not affect the performance of the trout (growth rate, haematocrit, erythrocyte fragility, absence of pathology, etc.) in this experiment. As stated earlier, the extent of oxidation of the oil was limited (see pages 444,445 ) and in some respects resembled the moderately oxidized oil used by Hung et al. (1980) in a practical diet. The oil they used was aerated at room temperature for $265 \mathrm{~h}$ during which time the peroxide value rose from 6.0 to $50.5 \mathrm{mmol} / \mathrm{kg}$ and the vitamin $\mathrm{E}$ content fell from 125 to $50 \mathrm{mg} / \mathrm{kg}$. Its inclusion, at a level of $75 \mathrm{~g} / \mathrm{kg}$, in practical diets supplemented with 33-99 $\mathrm{mg}$ DL- $\alpha$-tocopheryl acetate $/ \mathrm{kg}$, did not lead to any loss of performance nor to any pathologies in experiments carried out at $15^{\circ}$. Even when a more highly oxidized oil (aerated $1348 \mathrm{~h}$ at room temperature, peroxide value $60 \mathrm{mmol} / \mathrm{kg}$, vitamin E content zero) was used in the practical diet (Hung et al. 1981) there was no significant difference in weight gain, food conversion ratio or carcass composition from controls although there was an increase in mortality during weeks 9-24 and in erythrocyte fragility; these symptoms were eliminated when this diet was supplemented with $\alpha$-tocopheryl acetate $(33 \mathrm{mg} / \mathrm{kg})$. When fresh, non-oxidized fish oil was used in these practical diets no vitamin $\mathrm{E}$ deficiency symptoms occurred even in the absence of supplementation with $\alpha$-tocopheryl acetate. The measured level of tocopherol in this diet was $25 \mathrm{mg} / \mathrm{kg}$.

In contrast, the absence of supplementary vitamin $\mathrm{E}$ from the diets used in the present study (diets 2 and 4 ) had profound effects on the trout. Growth rate, food conversion ratio and fatty acid composition of hepatic polar lipids were all affected and, in particular, overt pathologies occurred in all the fish examined. By contrast with these results, trout given 
partially defined diets lacking supplementary vitamin $E$ in earlier experiments (Cowey et al. 1981, 1983) did not differ in any of these characteristics from control trout. Effects on erythrocyte fragility and ascorbic acid stimulated peroxidation of biomembranes from trout deficient in vitamin $\mathrm{E}$ were common to all experiments.

In these earlier experiments basal (adventitious) levels of vitamin $E$ in the deficient diets were zero (when the diet contained $10 \mathrm{~g}$ linolenic acid $/ \mathrm{kg}$ as essential fatty acid component) and $20 \mathrm{mg} / \mathrm{kg}$ (when the diet contained $100 \mathrm{~g}$ fish oil fatty acids $/ \mathrm{kg}$ as essential fatty acid component). The latter value was similar to the vitamin $E$ concentration in diet 2 in the present experiment, the former value lower than that. In line with this, tissue concentrations of vitamin E-deficient and control fish in the present experiment were very similar to those found in analogous treatments in previous experiments (for vitamin E-deficient fish $5.6 \mu \mathrm{g} / \mathrm{g}$ liver and $2.4 \mu \mathrm{g} / \mathrm{g}$ muscle, Cowey et al. $1981 ; 8.7 \mu \mathrm{g} / \mathrm{g}$ liver and $3.1 \mu \mathrm{g} / \mathrm{g}$ muscle, Cowey et al. 1983). Consequently the major differences - histopathology and other characteristics - between vitamin E-deficient fish in the present and in previous experiments seem to be related to other factors in addition to a low vitamin $\mathrm{E}$ intake.

One possible explanation of the results is that the severe myopathy observed was associated with a low level of dietary selenium, that is a combined deficiency of vitamin $\mathrm{E}$ and Se led to myopathies while a sufficiency of dietary vitamin $\mathrm{E}$ with low Se prevented them. No supplementary Se was added to the purified diets used in this experiment and measured dietary Se concentrations were only $0 \cdot 10 \mathrm{mg} / \mathrm{kg}$. In this connection it may be observed that Poston et al. (1976) found a supplemental Se level of $0.10 \mathrm{mg} / \mathrm{kg}$ to be adequate for Atlantic salmon (Salmo salar) of $0.9 \mathrm{~g}$ mean initial weight (calculated Se level in the basal diet $0.03 \mathrm{mg} / \mathrm{kg}$ ). Later Hilton et al. (1980) showed that a dietary Se level of $0.07 \mathrm{mg} / \mathrm{kg}$ (their lowest level) was sufficient to prevent Se deficiency symptoms in rainbow trout (dietary vitamin $\mathrm{E}$ level about $0.4 \mathrm{mg}$, water-borne Se level $0.4 \mu \mathrm{g} / 1$ ). While these observations do not rule out the possibility that myopathies in the present experiment were associated with a low dietary Se level they render it unlikely, especially as glutathione peroxidase activities did not differ between treatments and were of a similar or greater magnitude than those previously reported in salmonids (Poston et al. 1976; Hilton et al. $1980)$.

The principal differences between our earlier experiments and the one now reported are the physical conditions employed, especially the low temperatures pertaining toward the end of the experiment. The maintenance of fluidity in biomembranes is known to be more demanding, in terms of polyunsaturated fatty acids, at low than at high temperatures (Hazel, 1979) and it now appears that trout may be more susceptible to vitamin E deficiency at low water temperatures. Hung et al. (1981) laid emphasis on commercial situations in evaluating vitamin $\mathrm{E}$ requirement, having previously observed that there can be no single vitamin E requirement for rainbow trout under all practical situations (Hung et al. 1980). The present results indicate that water temperature warrants consideration as a factor in arriving at a vitamin $\mathrm{E}$ requirement for certain of these practical situations.

\section{REFERENCES}

Ackman, R. G. \& Eaton, C. A. (1978). Fette Seifen Anstrichm 80, 21-37.

Association of Official Analytical Chemists (1975). Official Methods of Analysis of the Association of Official Analytical Chemists, 12th ed. Washington, DC: AOAC.

Christie, W. W. (1973). Lipid Analysis. Oxford: Pergamon Press.

Cowey, C. B., Adron, J. W., Walton, M. J., Murray, J., Youngson, A. \& Knox, D. (1981). Journal of Nutrition 111, 1556-1567.

Cowey, C. B., Adron, J. W. \& Youngson, A. (1983). Aquaculture 30, 85-93.

Duncan, D. B. (1955). Biometrics 11, 1-42.

Folch, J., Lees, M. \& Sloane-Stanley, G. H. (1957). Journal of Biological Chemistry 226, 497-509.

Hasunuma, R., Ogawa, T. \& Kawanishi, Y. (1982). Analytical Biochemistry 126, 242-245. 

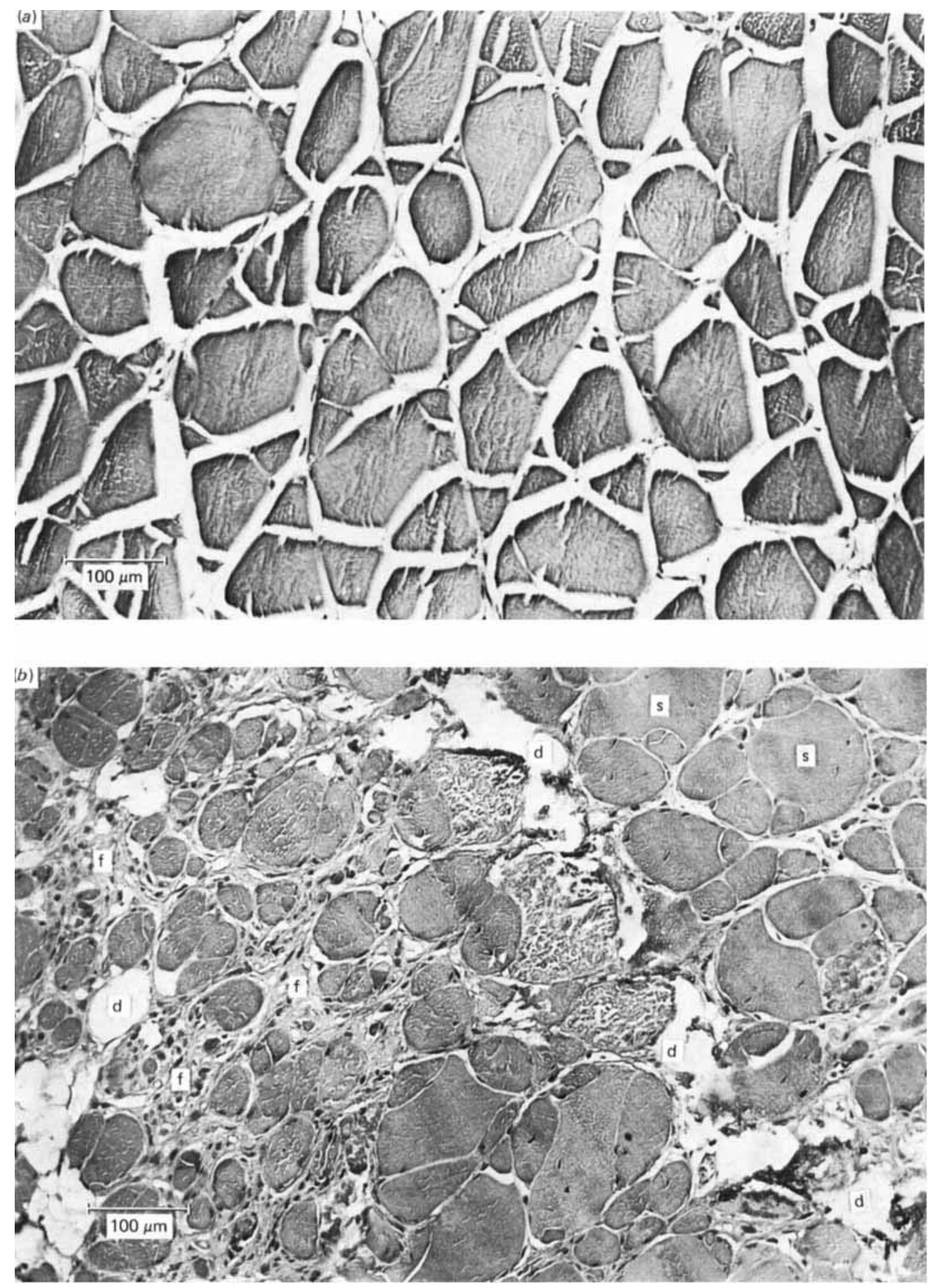

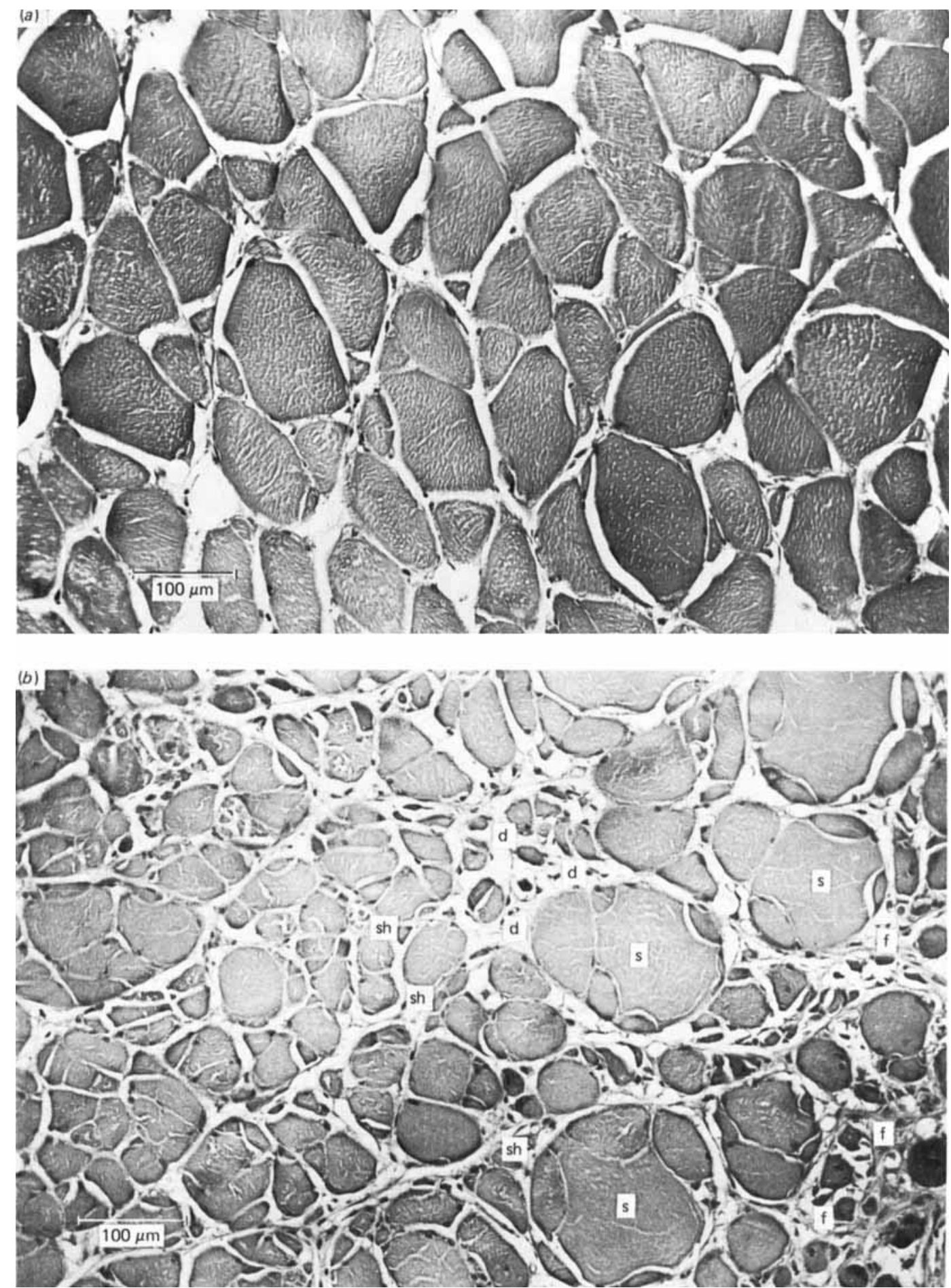
Hazel, J. R. (1979). American Journal of Physiology 236, R91-R101.

Hilton, J. W., Hodson, P. V. \& Slinger, S. J. (1980). Journal of Nutrition 110, 2527-2535.

Hung, S. S. O., Cho, C. Y. \& Slinger, S. J. (1980). Canadian Journal of Fisheries and Aquatic Sciences 37, $1248-1253$.

Hung, S. S. O., Cho, C. Y. \& Slinger, S. J. (1981). Journal of Nutrition 111, 648-657.

Kornbrust, D. J. \& Mavis, R. D. (1980). Lipids 15, 31 5-322.

McMurray, C. H., Blanchflower, W. J. \& Rice, D. A. (1980). Journal of the Association of Official Analytical Chemists 63, 1258-1261.

Poston, H. A., Combs, G. F. \& Leibovitz, L. (1976). Journal of Nutrition 106, 892-904.

Tacon, A. G. J. \& Cooke, D. J. (1980). Nutrition Reports International 22, 631-640.

Watanabe, T. \& Takashima, F. (1977). Bulletin of the Japanese Society of Scientific Fisheries 43, 819-830.

Watanabe, T., Takashima, F., Ogino, C. \& Hibiya T. (1970). Bulletin of the Japanese Society of Scientific Fisheries 36, 623-630.

Watanabe, T., Takeuchi, T., Wada, M. \& Uehara, R. (1981). Bulletin of the Japanese Society of Scientific Fisheries 47, 1463-1471.

\section{EXPLANATION OF PLATES}

Plate 1. (a), Skeletal muscle from trout given diet 1; normal appearance of tissue with fibre integrity maintained. Absence of fibroblasts and macrophages from inter-fibre space. (b), Skeletal muscle from trout given diet 2; fibres are all more rounded and some partly swollen (s). Some areas show hyaline degeneration (d) of muscle fibres and a proliferation of fibroblasts (f) in the interstitial spaces. For details of diets, see Table 1.

Plate 2. (a), Skeletal muscle from trout given diet 3, appearance typical of normal muscle. (b), Skeletal muscle from trout given diet 4; fibres have a rounded shape and some are partly swollen (s). Other fibres appear partly shrunken (sh). Zonal necrotic areas show eosinophilic hyaline degeneration (d). No macrophages are visible but in the interstitial spaces a proliferation of fibroblasts (f) has occurred. For details of diets see Table 1. 